\title{
REPRESENTAÇÕES E PRÁTICAS EDUCATIVAS DE MÃES REFERENTES A FILHOS ATENDIDOS PELO CONSELHO TUTELAR ${ }^{1}$
}

\author{
Daniel Henrique Pereira Espíndula* \\ Zeidi Araujo Trindade" \\ Maria de Fátima de Souza Santos
}

\begin{abstract}
RESUMO. Este estudo investigou as representações das mães atendidas pelo Conselho Tutelar sobre "filhos que dão problema" e práticas educativas. Participaram do estudo 11 mães de adolescentes envolvidos com drogas, em situação de rua e/ou praticantes de pequenos delitos. Utilizou-se um roteiro de entrevista com questões de evocação e questões abertas. $\mathrm{O}$ material foi trabalhado a partir da análise temática de Bardin. A representação das mães apresenta elementos como incontrolável, influenciável, de mente fraca e rebelde. As causas do problema parecem ser, principalmente: as características pessoais e internas; as amizades e o meio de convívio; falta de controle; necessidade de obter bens e questões religiosas. Já as práticas estão embasadas no diálogo e conselho. Não obstante, na concepção das mães, a única prática capaz de resolver o problema dos filhos seria a internação. Como esta medida geralmente não compete ao Conselho Tutelar, há um descompasso entre o desejo das mães e as medidas aplicadas pelo Conselho para a resolução do problema.
\end{abstract}

Palavras-chave: representação social, práticas de criação infantil, relações pais-criança.

\section{REPRESENTATIONS OF MOTHERS HELPED BY THE TUTORING COUNSEL AND THE EDUCATIONAL PRACTICES DEVELOPED IN FACING THE PROBLEM}

\begin{abstract}
This study investigated the representations of mothers helped by the Tutoring Counsel about "problem children"; the educational practices developed in facing the problem Eleven mothers of adolescents participated in the study, with children who presented some kind of problem - involvement with drugs, being at the street situation and/or practicing minor transgressions. We utilized an interview script with an evocation question, open questions. The material was analyzed using Bardin's thematic analysis. The results show that the representation of the mothers presents elements as: uncontrollable, weak mind and rebel. The causes seem to be centered in the personal and internal characteristics; friendships and the environment where they live; lack of control; need of acquirement of socially valued goods; and religious questions. The educational practices, though, are based on dialogue and advice. However, the mothers evaluate that the only practice capable of solving the problem of their children in internship. Nevertheless, what happens is that in most cases the application of this measure does not fall under the Tutoring Counsel capabilities, creating a gap between what is sought by the mothers and the measures applied by the Counsel in order to solve the problem.
\end{abstract}

Key words: Social representations, chilrearing practices, parent child relations.

\section{REPRESENTACIONES Y PRÁCTICAS EDUCATIVAS DE MADRES QUE MANDAN A LOS NIÑOS ACOMPAÑADOS POR EL CONSEJO PROTECTOR}

RESUMEN. Este estudio investigó las representaciones de las madres ayudadas por el Consejero de tutoría sobre "niños problema" y las prácticas educativas desarrolladas en el problema que enfrentan. Once madres participaron en el estudio, con niños que presentan algún tipo de problema, uso de drogas, siendo en la situación de calle y / o la práctica de transgresiones menores. Para la recolección de datos se utilizó un guión para la entrevista con cuestiones de evocación y preguntas abiertas.

1 Apoio: CNPq/Capes-Procad.

* Doutorando do Programa de Pós-Graduação em Psicologia da UFES e docente da Universidade Federal do Vale do Vale do São Francisco-UNIVASF.

\# Doutor em Psicologia. Docente do Departamento de Psicologia Social e do Programa de Pós-Graduação em Psicologia da Universidade Federal do Espírito Santo-UFES.

II Doutor em Psicologia. Docente do Departamento de Psicologia e do Programa de Pós-Graduação em Psicologia da Universidade Federal de Pernambuco-UFPE. 
El material se trabajó desde el análisis temático de Bardin. Los resultados muestran que la representación de las madres presenta elementos como: incontrolable, la debilidad de la mente y el rebelde. Las causas parecen estar centrados en el personal interno y características; amistades y el entorno donde viven, la falta de control; necesidad de adquisición de bienes valorados socialmente, y las cuestiones religiosas. Las prácticas educativas se basan en el diálogo y el asesoramiento. Sin embargo, las madres que la única medida práctica para resolver el problema de los niños sería la admisión. Todavía, no es conpetencia del Consejo de Tutela la aplicación desta medida. Lo que pasa es un desequilibrio entre lo que es deseado por las madres y las medidas aplicadas por el Consejo con el fin de resolver el problema.

Palabras-clave: Representación social, prácticas de crianza infantil, relaciones padres-niños..

A responsabilidade da família, mais particularmente da mãe, no processo de socialização dos filhos é tema recorrente na literatura psicológica, como mostram Rodrigues \& Trindade (1999). Em que pese a complexidade do processo de socialização, a Psicologia centrou-se, até meados do século XX, na análise do papel das relações familiares no desenvolvimento dos princípios éticos e morais. A centralização na família tem sua razão de ser, pois, por mais que as normas e os processos de socialização variem segundo os diversos contextos sociais, o papel dos pais ${ }^{2}$ continua sendo o de avaliar se os comportamentos dos filhos são ou não adequados a essas normas (Darling \& Steinberg, 1993, citado por Camino, Camino \& Moraes, 2003).

Ao mesmo tempo em que os pais se esforçam para promover o desenvolvimento de características socialmente valorizadas, esforçam-se também para suprimir ou reduzir comportamentos que sejam considerados socialmente inadequados ou desfavoráveis. Para cumprir o papel de agentes de socialização dos filhos, os pais utilizam-se de diversas estratégias e técnicas para orientar seus comportamentos, o que é denominado pela literatura de controle parental. Neste campo de estudo destacam-se como uma das contribuições mais importantes os trabalhos de Hoffman (1983, 1994) sobre a socialização, distinguindo três técnicas de socialização utilizadas pelos pais: a indução, a retirada de afeto e a afirmação de poder.

Em relação às práticas educativas de mães para com filhos, vários estudos apontam a relação entre modelos de estilos parentais e problemas relacionados à criação dos filhos (Pinheiro, 2003; Alvarenga \& Piccinini, 2001; Bolsoni-Silva \& Marturano, 2002; Camino, Camino \& Moraes, 2003; Weber, Viezzer \& Bradenbrug, 2004; Caldana, 1995). A esse respeito, Alvarenga \& Piccinini (2001) consideram que nas últimas décadas as práticas educativas parentais têm

2 Conforme argumentam Rodrigues e Trindade (1999), o uso genérico da palavra "pais", referindo-se a pai e mãe, muitas vezes mascara a pouca participação paterna no cotidiano dos filhos. sido objeto de estudos de inúmeras investigações. Segundo os autores,

\begin{abstract}
Muitas dessas pesquisas abordaram as possíveis implicações das práticas educativas utilizadas pelos pais no desenvolvimento de seus filhos. Entre outros fatores ligados ao desenvolvimento infantil, os problemas de comportamento têm sido enfatizados como uma das variáveis relacionadas às práticas educativas parentais (Alvarenga \& Piccinini, 2001, p. 449).
\end{abstract}

No caso dos jovens em situação de risco de envolvimento com práticas ilícitas ou em conflito com a lei, há em geral uma idéia socialmente compartilhada de que a família fracassou nas suas práticas socializadoras e, paradoxalmente, é a mãe a figura responsável por restabelecer os laços sociais desses jovens.

Espíndula e Santos (2004), ao investigarem as representações sociais de adolescente entre os Assistentes de Desenvolvimento Social, responsáveis pela guarda dos adolescentes autores de atos infracionais em regime de privação de liberdade, verificaram que esses adolescentes eram definidos como diferentes dos demais ancorados nas idéias de um determinismo biológico, os Assistentes de Desenvolvimento Social explicavam o envolvimento desses adolescentes com atos infracionais a partir de uma suposta carga genética herdada dos pais aliada a um ambiente de pobreza e violência.

Ao mesmo tempo, como ressaltam os autores, os educadores apontam a figura materna como a única capaz de reeducar aqueles adolescentes, uma vez que, segundo esses profissionais, a instituição responsável pelo processo de cumprimento das medidas socioeducativas não seria capaz de resolver o problema.

Lima (2003), ao entrevistar adolescentes em situação de liberdade assistida, verificou que a percepção da reação de sofrimento da mãe diante da infração representava para o adolescente um estímulo à superação e arrependimento da prática infracional. Sant'Ana (2003), ao verificar as representações da 
adolescência para os conselheiros tutelares do Espírito Santo, verificou que a família é vista por eles como a principal responsável pelo modo de ser do adolescente. Segundo a autora, estas concepções também se ancoram em produções da Psicologia do Desenvolvimento, que defende a família como a instituição responsável pela socialização dos filhos.

As representações sociais, tomadas como um sistema de interpretação, são capazes de conduzir a nossa relação com o mundo e com os outros e de orientar e organizar as condutas e comunicações sociais. Para Moreira (2001)

A teoria das representações sociais constituise num instrumento de estudo particularmente importante nas relações onde os aspectos simbólicos são determinantes das condutas, das práticas e dos comportamentos (Moreira, 2001, p. 104).

Dessa forma, o estudo das representações permitiria compreender o conjunto de significados atribuídos a um objeto por um determinado grupo social, bem como os comportamentos relativos a este objeto. A esse respeito, Vala (1996) argumenta:

\begin{abstract}
As representações sociais não são meros enunciados sobre a realidade, mas teorias sociais práticas sobre objectos relevantes na vida dos grupos. Enquanto teorias são organizações de crenças, atitudes e explicações; enquanto teorias práticas são organizações de acção; enquanto teorias sociais são produzidas no quadro das comunicações quotidianas suscitadas pelas identidades sociais (Vala, 1996, p. 151).
\end{abstract}

Diante desse quadro, como as mães de adolescentes em situação de risco de envolvimento ou envolvidos em práticas ilícitas representam seus filhos, e que práticas educativas elas desenvolvem no enfrentamento desse problema?

\section{MÉTODO}

\section{Participantes}

A pesquisa foi realizada no município de Vitória ES, com 11 mães de adolescentes atendidos pelo Conselho Tutelar do mesmo município, selecionadas previamente, por telefone, pelo Conselho Tutelar de Vitória, segundo os critérios estabelecidos para a pesquisa: filhos que apresentem algum tipo de problema para os pais, tais como uso de drogas, estarem em situação de rua e/ou praticando pequenos delitos. O número de mães a serem entrevistadas foi determinado pelo critério de saturação, isto é, na medida em que o conteúdo trazido durante a situação de entrevista já estava se repetindo em torno de alguns eixos temáticos, a coleta foi finalizada.

\section{Instrumento de coleta de dados}

Foram realizadas entrevistas individuais com roteiros semi-estruturados junto às mães atendidas pelo Conselho Tutelar. $\mathrm{O}$ roteiro de entrevista continha questões que abordavam os aspectos sociodemográficos das respondentes, além de questões abertas agrupadas em torno do filho adolescente que estava apresentando problemas e das práticas educativas para o enfrentamento da questão. Todas as entrevistas foram gravadas e realizadas durante visitas às residências das mães. Para garantir o sigilo, todos os nomes contidos nos relatos apresentados foram modificados.

\section{Procedimento de análise dos dados}

Dentre as diversas modalidades de análise propostas por Bardin (1979), a análise temática pareceu a mais apropriada, uma vez que se pretendeu identificar determinados temas que denotam os valores de referência e formas de conduta presentes no discurso. As categorias estabelecidas não são excludentes. A análise foi dividida em dois eixos: as representações sociais das mães sobre os filhos e as práticas desenvolvidas por elas para enfrentar os problemas existentes.

\section{RESULTADOS E DISCUSSÃO}

Representação social das mães sobre o filho "adolescente que dá problemas"

As explicações dadas pelas mães para o comportamento de seus filhos foram agrupadas em cinco categorias de análise: características pessoais e internas; amizades e o meio externo em que vivem; questões familiares; questões religiosas e necessidade da obtenção de bens socialmente valorizados.

"Características pessoais e/ou internas" foi a categoria que obteve maior freqüência de resposta entre as mães para explicar o "mau comportamento" do filho. Esse dado pode indicar a busca de uma causa "concreta" que permita um tratamento e, conseqüentemente, a eliminação do problema.

É comum aparecerem nos relatos termos como: "mente ou cabeça fraca", "defeito" ou "coisa que veio de dentro dele", por exemplo. Assim, segundo as 
mães, a causa dos problemas apresentados pelos adolescentes tem origem em atributos pessoais e características da personalidade dos adolescentes. Aqui esses atributos, tomados como valor de verdade, são capazes de prescrever práticas, sejam de caráter educativo ou de atenção à saúde.

$\mathrm{Na}$ maioria das vezes as mães levantam a possibilidade de o filho ter algum distúrbio de ordem cognitiva, tais como a incapacidade de internalizar regras morais. Com frequiência relatam ter procurado ajuda médica a fim de realizar exames para descobrir se o problema tem como causa algum transtorno psiquiátrico:

Rodrigo eu vou fazer algum exame nele para ver se ele tem algum problema. Ele é muito rebelde mesmo. Pode ser problema de cabeça, meio doido sei lá (...) Sei lá o que Rodrigo tem, o que passa na cabeça de Rodrigo. Uma hora ele está bom, de repente ele fica nervoso, qualquer hora ele briga (Participante 2).

$\mathrm{Na}$ medida em que as mães atribuem os problemas de comportamento dos filhos a uma causa naturalizada, conseguem justificar a sua impossibilidade de controlá-los. Nessa perspectiva, as práticas educativas maternas seriam ineficazes, uma vez que o problema estaria localizado em causas internas, em características individuais. Ao fazerem uso de tais justificativas estas mães estariam afastando a possibilidade de se colocar na posição de culpadas, evitando, assim, que o seu papel de "boa mãe" seja questionado. Ademais, resguardariam a representação de boa mãe e os valores a ela associados e justificariam a ineficácia das práticas educativas.

Aqui, diversas representações e práticas se interligam a partir de um enjeux social para guiar as condutas desses atores sociais e dar-lhes sentido. Assim, a representação do adolescente que apresenta problemas se interliga à representação da maternidade, de filho, família, modelo educacional, bem como à noção de que o meio social exterior à família é potencialmente perigoso (Da Matta, 1997). O perigo é concretizado nas amizades do adolescente e no meio externo, capazes de levar os filhos para o mau caminho.

Geralmente, as participantes também atribuem à influência das más amizades o fato de seus filhos estarem na rua ou envolvidos com o tráfico de drogas. Durante a realização das entrevistas era comum as mães relatarem que os maiores problemas enfrentados com o filho estavam relacionados ao uso de drogas. Nesses momentos, elas baixavam o tom de voz ou pediam que não fosse registrado o que iriam dizer, uma vez que os traficantes que vendiam droga para o filho eram seus vizinhos ou pessoas muito próximas a ela. A má companhia freqüentemente apareceu como o fator que levou o filho a trilhar esse caminho. $\mathrm{O}$ relato a seguir explicita bem essa questão:

O problema dele é a companhia, porque se está junto, o que um faz todos querem fazer, e aí vai desse jeito. Se ele fosse uma criança sozinha ele não agiria desse jeito que ele age. Se ele fosse uma criança que não vivesse com as outras crianças, ele não agiria da forma que age, ele seria melhor (participante 4).

A afirmação das mães de que o seu filho mudou de comportamento após irem morar numa nova comunidade corrobora a posição de Harris (1995) ao considerar o papel dos pares como decisivo na formação de crianças e adolescentes. Essa autora faz o seguinte questionamento:

Por que tantas crianças nesses bairros se
evadem da escola, engravidam e cometem
crimes? É por que não têm pai? Essa é uma
explicação popular (...). Os bairros têm
culturas diferentes e as culturas tendem a se
auto perpetuar; elas passam do grupo de
pares dos pais para o grupo de pares das
crianças. O meio através dos quais as
culturas são passadas não pode ser a família,
porque se você tirar uma família de um bairro
e colocá-la num outro lugar qualquer, o
comportamento das crianças mudará para se
adequar ao dos seus pares do novo bairro
(Harris, 1995, p.381-382).

Numa pesquisa realizada por Santos e Aléssio (2006), as autoras também apontam que pais de classe média do Recife consideram que as amizades são um dos maiores problemas trazidos pelos filhos. Para esses pais, é o outro, concretizado nas relações de amizade dos adolescentes, o responsável pelas drogas, o álcool, a gravidez e a violência.

Ao que parece, para as mulheres entrevistadas, as principais causas que levam o adolescente a sair do controle são exteriores à mãe ou aos responsáveis pela educação desses jovens. Apesar de reconhecerem as dificuldades em educar os filhos, as mães avaliam suas práticas educativas como eficazes na transmissão de normas e valores sociais. Colocar em questão essas práticas é deixar um espaço aberto para pôr em questão a sua imagem de boa mãe.

A terceira categoria que emerge na definição das mães sobre o adolescente com problemas diz respeito, 
paradoxalmente, às questões familiares. Temas relativos à criação dos filhos, como o excesso de "dengo" na educação, a ausência do pai e questões de hereditariedade são também apontados como prováveis causas do problema.

A Psicologia do Desenvolvimento conta com numerosos estudos a respeito da importância da interação parental e das práticas educativas utilizadas pelos pais sobre o desenvolvimento de crianças e adolescentes (Alvarenga \& Piccinini, 2001; BolsoniSilva \& Marturano, 2002; Weber, Viezzer \& Bradenbrug, 2004). As práticas educativas, nestas perspectivas, referiam-se às estratégias utilizadas pelos pais para atingir objetivos específicos em diferentes domínios (acadêmico, social, afetivo) sob determinadas circunstâncias e contextos. O uso de explicações, de punições e recompensas constitui um exemplo dessas práticas (Cecconello, Antoni \& Koller, 2003).

A não-utilização da força física na educação infantil é fruto de mudanças nas relações familiares ocorridas a partir do processo de modernização societária que ocorreu no Brasil desde as décadas de 1940 e 1950. Neste período teve início a substituição do modelo da família hierárquica pelo modelo de família igualitária, prevalecendo a concepção de igualdade acima das diferenças. As noções antes bem delineadas do que era certo e errado perderam seu valor, prevalecendo a pluralidade de escolhas, cuja única limitação é a individualidade do outro (Caldana,1995).

Entretanto, a autora salienta que esta mudança não se operou sem dificuldades, gerando angústia e conflitos entre os dois modelos. A prática da punição da criança persiste ainda hoje como uma prática educativa. $\mathrm{O}$ discurso das mulheres entrevistadas parece refletir essa tensão entre práticas educativas decorrentes de modelos diversos de família. Ao fazerem referência à não-utilização com frequiência dessa prática pouco valorizada, as mães passam a crer que o excesso de "dengo" ou a não-punição da criança com castigos físicos associada às questões internas das crianças, poderiam ter atrapalhado a educação desses filhos. Nessa perspectiva, o excesso de amor, característico do papel de boa mãe, teria trazido consequiências negativas para o filho.

Acho que ele foi muito mimado, sei lá. Ele era muito carinhoso, muito bonzinho. Acho que eu dei muito dengo, ele era só um menino, só tinha ele de menino e todo mundo ficava dando dengo a ele até grande (participante 2).
São também freqüentes as explicações ancoradas em teorias psicológicas sobre os possíveis danos causados pela ausência paterna durante o desenvolvimento infantil. Apesar de a ausência paterna ser um argumento bastante evocado, as entrevistadas afirmam também não acreditar nessa justificativa. O trecho abaixo de uma entrevista é capaz de exemplificar essa questão:

Sei lá, ou às vezes pode ser revolta também por ter sido criado sem pai. Mas isso não, porque eu também fui criada sem mãe e nem por isso eu cresci revoltada, uma parte e em outra não. Eu não sei te dizer (participante $6)$.

A atribuição de causalidade à consangüinidade também apareceu na categoria questões familiares. Quando se referiam aos possíveis problemas que pudessem levar o filho a ser daquela forma, o "sangue ruim" do pai costumava ser evocado. Para essas mães, comportamentos e atitudes dos adolescentes como a "propensão a ir para a rua" ou não querer obedecer aos mais velhos teriam sua causa na hereditariedade, mais especificamente, no gene paterno.

Eu não sei por que ele é assim. Mas a família do pai dele, por exemplo, o pai dele e o tio, não eram muito certos. $O$ pai consertou, lógico. Hoje o pai dele é uma pessoa certa, mas o pai na época não era uma pessoa certa e o tio também não. Às vezes, eu me perguntava: será que não puxou? Porque se na família não existe... (participante 6).

Joffe (2003), ao investigar o surgimento da Aids entre os ingleses e sul-africanos, mostrou como esses povos atribuem o surgimento da doença ao outro, a partir de elementos negativistas. Trindade (1991), ao verificar as representações de paternidade e maternidade no processo de aconselhamento genético, encontrou resultados semelhantes aos do presente estudo. Do mesmo modo, as mães entrevistadas atribuíam as causas da "doença" dos filhos ao outro, ou seja, ao lado paterno da família. Nessa perspectiva, relatavam a existência de diversos casos de outras doenças e vícios na família do companheiro, o que "comprovaria" uma carga genética de má qualidade do pai que havia sido transmitida ao filho.

A atribuição de causalidade ao outro parece fazer parte do processo de objetivação e serve ainda à manutenção da representação social de "boa mãe". Ao atribuir às características genéticas do pai o comportamento problemático do adolescente, as mães, de certa forma, isentam-se mais uma vez da 
possibilidade de culpa e de questionamento de suas práticas educativas. Emergem processos simbólicos que visam, em última instância, preservar a integridade e a identidade materna.

A maternidade, longe de ser um fenômeno puramente biológico, insere-se em uma rede de significados ligados às concepções de homem, mulher, filho e família. Circula em nossa sociedade a idéia compartilhada de que a função materna é o ponto culminante do desenvolvimento da mulher e que se delineiam, com certa nitidez e precisão, os contornos que definem a experiência de maternidade. Ser mãe é uma condição "natural" do gênero feminino e, para sêlo, é indispensável seguir determinados esquemas comportamentais e sentimentais que garantam o aperfeiçoamento físico e psíquico de sua prole.

Santos, Novelino e Nascimento (2001, p 273) chamam a atenção para o discurso psicológico que "supõe um vínculo inevitável mulher-mãe, assim como confere à mãe a responsabilidade integral pela criação da prole sob o argumento de que a mulher é naturalmente dotada de um saber que a orienta no desempenho dessa função". Nessa lógica social, portanto, não apenas se funde mulher e maternagem, mas também se estabelecem critérios sobre o que significa ser uma boa mãe. Essas representações sociais parecem ser hegemônicas em nossa sociedade e se constituem como quadro de referência na avaliação que fazem os outros e as próprias mulheres do seu desempenho materno (Santos, Novelino \& Nascimento (2001).

Outra categoria que emerge do discurso das mães é necessidade de consumo e questões religiosas. Explicações de cunho mágico-religioso são elementos que possibilitam explicar a realidade que cerca as mães. Grande parte delas declara ser praticante de algum tipo de culto religioso, sendo a maioria participante de igrejas pentecostais e/ou neopentecostais. As explicações para o problema do filho estão situadas em torno de um "encosto", espíritos ou entidades místicas que se apossaram do adolescente e o levaram a ir para a rua.

O que leva ele a fazer isso foi um encosto. Já foi revelado isso na Igreja. É um encosto mesmo que ele tem. Eles falaram que é um negócio familiar. Porque o pai do meu pai sumiu também assim que ninguém sabe dar notícia, o meu pai também sumiu que ninguém sabe dar notícia, e agora foi o Rodrigo que estava sumindo. Eu já sei o que isso é. Mas agora ele já está liberto. Agora não tem mais não (participante 2).
As justificativas empregadas pelas mães são múltiplas e contemplam as mais diversas esferas explicativas, aparentando por vezes contradição, mas quase todas conservam um ponto comum: afastam a responsabilidade da mãe. Essa atribuição de causas diferentes apresentadas algumas vezes por uma única mãe é interessante do ponto de vista teórico, pois revela o sincretismo explicativo.

Do ponto de vista teórico, a abordagem estrutural das representações sociais, tomada como uma ferramenta teórica, fornece uma explicação para essa aparente contradição. Para Abric (1994), a representação social é um conjunto organizado e estruturado de significados constituído de dois subsistemas relacionados: o sistema central (ou núcleo central) e o sistema periférico. O núcleo central garante a significação, a organização interna e a estabilidade da representação, portanto é uma estrutura resistente à mudanças. $\mathrm{O}$ sistema periférico, por sua vez, é formado por um conjunto de elementos que se adaptam facilmente às alterações cotidianas do contexto social imediato, portanto, adaptáveis a cada situação. Por estarem ligadas ao contexto imediato e situacional, essas mães são capazes de empregar diferentes justificativas que se adaptam facilmente ao meio, como problemas internos, hereditariedade, religiosidade ou necessidade de bens de consumo, visando afastar possíveis questionamentos que venham a ameaçar os elementos do núcleo central.

A passagem da justificativa de elementos de ordem espiritual para as coisas materiais segue a mesma lógica de atribuir o comportamento do filho a causas externas para explicar o fato. Esse procedimento denota uma tensão entre alívio e culpa, na medida em que independe da mãe essa busca, pois é sua condição social que não lhe permite dar ao filho aquilo que ele deseja. $\mathrm{O}$ comportamento problemático é, então, explicado através da necessidade de obtenção de objetos socialmente valorizados: tênis, celular, roupas de grife, óculos escuros, bonés, etc.

Olha, para educar um filho hoje no momento eu acho que depende não só da mãe estar falando, explicando. A situação financeira também ajuda bastante, porque, no caso do Max mesmo, às vezes ele pede um tênis, isso ou aquilo e eu não tenho condições de dar e ele fala: Ah, porque eu vou vigiar carro, vou fazer isso, vou fazer aquilo. Então se fosse da minha livre e espontânea vontade ele não faria, entendeu? Então eu acho que muitas vezes a condição financeira tem aquela parcela de culpa da gente não poder dar aquela educação, aquela coisa, porque eu vejo, do contrário de muitas famílias que tem 
por aí, que sempre que podem na medida do possível, precisa de uma roupa, de um calçado ou alguma coisa e os pais têm condições de dar, que nem eu tenho experiência com até alguns vizinhos mesmo: estuda melhor, pensa diferente (participante 9).

As mães entrevistadas parecem supor que, se pudessem oferecer os bens materiais desejados pelos filhos, não enfrentariam alguns dos problemas vividos no presente, pois isto evitaria o envolvimento dos filhos com práticas ilícitas que têm como objetivo último a obtenção do objeto valorizado. A justificativa das mães de que o filho vai buscar na rua uma forma de obtenção de bens corrobora os achados de Santana, Doninnelli, Frosi e Koller (2005), pois segundo estas autoras:

O ganho financeiro obtido nas ruas é uma das questões mais difíceis de ser discutida e avaliada quando se estuda a realidade dos adolescentes em situação de rua. Afinal esta é uma das razões que motivam os adolescentes a preferirem a rua a outros ambientes. A atual situação econômica do país faz com que um número expressivo de famílias sobreviva abaixo da linha da miséria, tornando atraente a possibilidade de conseguir diariamente ganhos significativos através da mendicância e outras atividades, algumas vezes ilícitas. Estes valores são utilizados para a aquisição de alimentos, vestimentas, drogas e financiamento de atividades lúdicas, tais como, fliperamas e vídeo games (Santana et al., 2005, p. 137).

Entretanto, apesar de aceitarem que todos esses elementos contribuem para a perda do controle dos filhos, as mães, como veremos mais adiante, nas suas práticas educativas visam, na medida do possível, à resolução de tais problemas. Ao atacar as causas procurando uma igreja para resolver o problema do "encosto" ou levando o filho ao médico para fazer exames a fim de verificar um possível transtorno mental, elas demonstram que ainda realizam certo investimento nos filhos e que ainda não desistiram de lutar para que suas práticas sejam mais eficazes. A busca pelo Conselho Tutelar seria uma dessas alternativas - algumas vezes, desesperadas - de tirar seus filhos da rua e do mundo das drogas.

\section{Práticas desenvolvidas pelas mães visando à resolução do problema do filho}

As práticas educativas descritas pelas mães para os problemas apresentados pelos filhos são: tentar educar e dar exemplo; dialogar/dar conselho; levar para a escola; pedir ajuda a Deus; procurar ajuda externa; internar; deixar de lado.

$\mathrm{Na}$ categoria tentar educar e dar exemplo encontramos algumas práticas desenvolvidas desde a infância, como a de bater e colocar de castigo e a de tentar educar o filho por meio de ensinamentos morais. Durante a entrevista, a participante 4 relata como procura educar seu filho:

Eu acho que chamando, dando conselho, conversando, chamando a atenção, mostrando o que é bom e o que é ruim, sempre mantendo ele na escola antes de ser pior, de não poder mais controlar. Porque o daqui mesmo, eu fazendo isso está fora do meu controle e eu nem mesmo sei o que fazer, como agir com ele mais, como aconselhar. Porque ele não ouve nada, não ouve conselho, não ouve as pessoas que querem ajudar.

A persistência dessas práticas parece ancorada na idéia do diálogo, bastante valorizada atualmente (Caldana, 1995; Alvarenga \& Piccinini, 2001). Tentase educar o filho por meio de conselhos e ensinamentos de ordem moral quanto ao que se pode ou não fazer, bem como as possíveis conseqüências:

Ele toma banho, janta e eu converso, falo: dentro de casa você vai ficar indo para a escola, andando certo, não quero reclamação na minha porta, porque ele aprontava. Falo com ele, ele prefere escolher a rua (participante 6).

A adoção de práticas conciliatórias em vez das punitivas provavelmente está ancorada nas idéias difundidas pela Psicologia do Desenvolvimento, o que demonstra a apropriação desses conhecimentos pelo senso comum. Caso o filho não siga o que foi preconizado pelas mães, estas passam a utilizar medidas mais severas. Usar a força física ou colocar os filhos de castigo constituem práticas mais severas para abolir o comportamento indesejado do filho. Contudo, tal prática, considerada eficaz para a resolução dos problemas do filho, não é vista com bons olhos pela justiça, segundo as mães:

Desde que tem vez também que o próprio filho também não colabora muito não, porque antigamente os pais davam uma boa surra, botava eles de castigo e tinha que funcionar, né? Mas hoje diante de tantas normas, que o pai não pode fazer isso, não pode fazer aquilo, a gente se sente até um 
pouco ousado (...) porque hoje a gente não pode bater. A gente bate de ousado, mas se a gente der um tapa na criança, se vier um denúncia a gente vai preso (Participante 9).

O receio de lançar mão de práticas coercitivas mais severas, como o uso da força física, por exemplo, gera um sentimento de perda de poderes sobre a educação do filho. Mesmo argumentando que a prática do aconselhamento e do diálogo seja a mais utilizada, para as mães entrevistadas o uso de palmadas é visto como uma prática eficaz em vários casos, embora expressem o temor de sofrer represálias das autoridades competentes.

Incentivar a ida do filho à escola foi também uma prática freqüentemente citada entre as participantes. A escola aparece, no discurso das mães, como um espaço capaz de, quando não reconduzir o filho ao caminho desejado, mantê-lo afastado das fontes geradoras do problema:

\begin{abstract}
"Eu para mim, uma coisa que teria me ajudado bastante era o caso da escola. (...) então eu penso assim, que o que teria me ajudado um pouco seria isso aí, porque hoje ele não está na escola. Eu procurei a escola e eles me falaram que não tinha jeito. Inclusive eu fui, fiz a matrícula dele tudo certinho. Quando ele chegou lá para estudar, aí eles falaram que não tinha vaga para ele" (participante 9).
\end{abstract}

O que estaria motivando essas mães a valorizar a escola não seriam apenas os possíveis benefícios que a escolaridade poderia proporcionar, mas a expectativa de uma ação preventiva para evitar problemas futuros. $\mathrm{O}$ interesse das mães economicamente menos favorecidas em encontrar um local para manter os filhos longe dos perigos que a rua oferece aparece aqui na preocupação em manter o filho na escola e, mais adiante, com o forte desejo de encontrar um local para interná-lo.

Constatou-se ainda que, durante a entrevista, muitas mães relataram procurar como fonte externa de ajuda o Conselho Tutelar. Na verdade, a maioria delas foi procurada pelos técnicos do Conselho, que, alertados pela escola ou por denúncias sobre os problemas enfrentados pelos adolescentes, estabeleceram contato com as famílias. $\mathrm{O}$ trecho abaixo retirado de relato de uma mãe é capaz de exprimir os sentimentos e primeiras sensações vivenciados por ela:

Eu já tinha ouvido falar do Conselho. Aí eu depois fui lá levar. Aí a professora mandou eu levar, aí eu levei. Mas ele quando do Conselho voltou ele melhorou. Só que depois de um tempo para cá, que ele se achou que tá grande, que é dono do mundo. $O$ outro filho eu também já leve" (participante 1).

Os resultados apresentados pelos adolescentes após visita ao Conselho Tutelar no início são sempre satisfatórios. As mães salientam que os filhos melhoraram, passaram a ficar mais tempo em casa, passaram a ser mais obedientes e tranqüilos. Entretanto, esta fase de tranqüilidade durava pouco tempo. Após perceberem que nenhuma pena ou atenção mais cuidadosa era aplicada, o adolescente voltava a praticar os mesmos atos que o haviam levado a ser atendido pelo Conselho Tutelar, gerando desespero e preocupação para as mães.

Na concepção dessas mães, as ações do Conselho Tutelar são pouco eficazes por serem de pouca duração. Elas defendem, por consequiência, medidas mais duras a serem aplicadas aos seus filhos. Ao invés do comparecimento ao Conselho Tutelar para conversar e ser informados sobre a sua situação, o que as mães realmente desejam é que seus filhos sejam encaminhados para instituições de internação, medida essa que, na maioria das vezes, não compete ao Conselho Tutelar. Um trecho das entrevistas das participantes 5 expressa bem essa preocupação:

\begin{abstract}
O Alexandre me chamou lá, eu fui lá e procurei ele para ajudar. Vai dar três anos que está cuidando disso aí. Ele me deu o telefone da abordagem de rua, as meninas que trabalham na abordagem para ver se conseguiram alguma coisa para internar ele, mas tem uma coisa: só interna se ele quiser, mas aí não tem como, só interna se ele quiser.
\end{abstract}

As medidas de internação constituem uma modalidade de ação que, como veremos adiante, é perseguida pelas mães como a única solução capaz de resolver o problema do seu filho, não importando se essa internação tenha por finalidade a realização de algum tipo de tratamento específico ou a reclusão em alguma unidade responsável pelo cumprimento de medidas socioeducativas. Ao que nos parece, muitas vezes essa internação é desejável para se retirar o adolescente do morro ou do contato com os atuais companheiros. A internação serviria, assim, como proteção para o adolescente.

Esse desejo de internação do filho surge aqui como, talvez, a última e única medida percebida por elas como efetivamente capaz de solucionar o 
problema dos filhos. Esta prática parece ser procurada com afinco, como podemos ver:

\begin{abstract}
Só pegar e internar ele, só isso. Porque eu já peguei e procurei o Conselho há três anos. Há três anos que eu estou nessa luta. Já procurei esse tipo de ajuda sim. Mas eles disseram que só internam a criança se ele quiser (participante 5).
\end{abstract}

Esse interesse em encontrar um local para internar seus filhos é tão grande que, durante as entrevistas, as mães afirmaram reiteradamente ter procurado se informar a respeito de possíveis instituições que pudessem abrigar seus filhos, sejam elas entidades de cunho religioso, filantrópico ou público. O importante é proteger o filho retirando-o de um contexto de ameaça.

Diversas são as tentativas dessas mães para solucionar os problemas trazidos pelos filhos e protegê-los da ameaça da rua. Ao se depararem com a ineficácia das práticas conhecidas e esperadas socialmente de uma boa mãe (diálogo, castigo, igreja, escola), elas buscam ajuda externa. O Conselho Tutelar aparece assim como possibilidade de solução.

Por outro lado, os educadores sociais responsáveis pelo processo socioeducativo de adolescentes em privação de liberdade consideram que as práticas educativas da mãe seriam a única alternativa capaz de prevenir a entrada e/ou permanência de adolescentes nas situações de conflito com a lei (Espíndula, 2003).

Ao que parece, tanto a família como as instituições responsáveis pelo cumprimento de medidas socioeducativas, representadas pelos seus funcionários, percebem as suas práticas como ineficazes para a resolução do problema enfrentado pelos adolescentes. Ao crer na ineficácia de suas ações, cada grupo tende a atribuir a competência para o outro. Dessa forma, as mães deslocam a possibilidade de recuperação para as instituições de internamento e estas repassam a responsabilidade para a família, mais especificamente, para a mãe, que, segundo os educadores, é responsável por mediar as normas e os valores sociais bem como o vínculo familiar mais presente na vida dos adolescentes.

Outras mães, após procurarem várias fontes externas de ajuda, como a igreja, associação de moradores, Conselho Tutelar, etc., ao verem que o esforço dispendido não rendeu o resultado esperado, desistem de continuar lutando para resolver $o$ problema trazido pelo filho. Argumentam estar cansadas de perder batalhas, a maioria delas para a droga, outras para a própria vontade do adolescente em continuar no mundo do crime, praticando pequenos furtos e/morando na rua.

\begin{abstract}
Não, eu acho que tudo o que eu fiz, eu fiz para o bem dele. Faria sim, tudo de novo, a gente quer ajudar um filho. Igual ao que eu te falei, eu cansei, quebrei muito a cabeça, nada deu jeito. Como se diz, entreguei na mão de Deus... um dia chegaram na minha porta com ele, porque eu já falei para você que eu não apóio, aí eu estava sozinha com as minhas duas filhas e os policiais falaram que eu tinha que acompanhá-los. Eu virei para o policial e falei que não ia acompanhar eles porque eu estou com as minhas duas filhas dormindo dentro de casa e estou sozinha, ele não mora dentro de casa e fica na rua aprontando e depois vem procurar o caminho de casa quando apronta. Vocês levem ele, que no outro dia eu vou lá e resolvo o problema (participante 6).
\end{abstract}

\section{CONSIDERAÇÕES FINAIS}

Ao longo deste trabalho, discutimos a temática das representações das mães atendidas pelo Conselho Tutelar sobre filhos que dão problemas e as práticas educativas desenvolvidas visando à sua resolução.

A partir da análise dos resultados foi possível observar que as explicações das mães a respeito dos adolescentes que dão problemas parecem construídas sobre a tensão entre elementos da natureza, da cultura ou elementos de ordem espiritual. Para elas, a causa dos problemas gira em torno das características pessoais e/ou internas, da "carga genética" herdada da família paterna (elementos da natureza), da falta de limites, do meio no qual o adolescente vive, da necessidade de adquirir bens de consumo socialmente valorizados, da aquisição de substâncias ilícitas (elementos da cultura), além de questões religiosas, como "encostos" e maldições familiares (elementos espirituais).

Foi também de interesse da pesquisa compreender como se dá a articulação entre as representações de "adolescente que dá problema" e as práticas educativas relativas a esses adolescentes. É importante salientar que as práticas educativas desenvolvidas pelas mães parecem estar sendo guiadas não apenas pela representação de "filho que dá problema", mas também por um sistema de representações que inclui as representações de maternidade e de boa mãe, por exemplo. 
Estes pontos remetem à discussão, já mencionada por Almeida, Santos e Trindade (2002), sobre a articulação de diversas representações na orientação de práticas relativas a um dado objeto, ao mesmo tempo em que nos indicam a diversidade de práticas sociais, articuladas no cotidiano, que podem orientar as representações sociais de um objeto específico.

Jodelet e Moscovici (1990) atentam para o fato de que as práticas sociais são estudadas aquém do desejado pela Psicologia Social, apesar de sua importância teórica. E observam:

\begin{abstract}
Considera-se, geralmente, que as representações sociais são associadas a comportamentos atomizados, sem laços sociais, freqüentemente sob a forma de legitimação, dando sentido aos atos que lhes são anteriores ou independentes. Negligencia-se o fato que as práticas são sistemas de ações socialmente estruturados e instituídos em relação com regras (Jodelet \& Moscovici, 1990, p.287).
\end{abstract}

Observa-se a partir dos dados apresentados que as práticas educativas construídas pelas mães na busca de resolver o problema de seus filhos relacionam-se às práticas religiosas, por exemplo, e a um sistema que inclui a representação de filho, de mãe e de família.

Como salienta Trindade (1998) em relação à configuração das práticas, estas não devem ser tratadas como se "fossem desvinculadas de outras práticas construídas pelos sujeitos e sem existência (ou relevância) em outros momentos de suas vidas" (Trindade, 1998, p.20).

Os dados aqui apresentados demonstram a complexidade da relação entre representação e práticas sociais. Mais coerente do que afirmar que as representações orientam as práticas, talvez seja falar de um sistema de representações capaz de orientar as práticas desenvolvidas pelos mais diversos atores sociais. Tendo por base os nossos achados, pensar a relação entre práticas e representações a partir de um sistema de representações parece ser a proposta mais adequada para a compreensão de suas possíveis relações.

\section{REFERÊNCIAS}

Abric, J.-C. (1994). Pratiques sociales et représentations. Paris: P.U.F.

Almeida, A. M. O., Santos, M. F. S. \& Trindade, Z. A. (2002). Representações e práticas sociais. Temas de Psicologia, 8(3), 257267.
Alvarenga, P. \& Piccinini, C. (2001). Práticas educativas maternas e problemas de comportamento em pré-escolares. Psicologia: Reflexão \& Crítica, 14(3), 449-460.

Bardin, L. (1979). Análise de conteúdo. Lisboa: Edições 7.

Bolsoni-Silva, A. T. \& Marturano, E. M. (2002). Práticas educativas e problemas de comportamento: uma análise à luz das habilidades sociais. Estudos de Psicologia, 7(2), 227-235.

Caldana, R. H. L. (1995). A educação de filhos em camadas médias: transformações no ideário e orientações de pais. Temas em Psicologia, 13(1), 109-121.

Camino, C., Camino, L. \& Moraes, R. (2003). Moralidade e socialização: estudos empíricos sobre práticas maternas de controle social e o julgamento moral. Psicologia Reflexão \& Crítica, 16(1), 41-61.

Cecconello, A. M., Antoni, C. \& Koller, S. H. (2003). Práticas educativas, estilos parentais e abuso físico no contexto familiar. Psicologia em Estudo, 8(Esp), 45-54.

Da Matta, R. (1997). A Casa \& a Rua (5 ed.). Rio de Janeiro: Rocco.

Espíndula, D. H. P. (2003). “Eles são Diferentes...” Representações dos Educadores Sociais de Adolescentes em Conflito com a Lei Sobre Adolescência e Violência. Monografia, Departamento de Psicologia, Universidade Federal de Pernambuco, Pernambuco.

Espíndula, D. H. P. \& Santos, M. F. S. (2004). Representações sobre a adolescência a partir da ótica dos educadores sociais de adolescentes em conflito com a lei. Psicologia em estudo, 9(3), 357-367.

Harris, J. R. (1995). Diga-me com quem anda... : Quem realmente conta na formação - os pais ou os amigos? Quais os caminhos para o desenvolvimento de uma criança? Rio de Janeiro: Objetiva.

Hoffman, M. L. (1983). Affective and cognitive processes in moral internalization: An information processing approach. In E. T. Higgins, D. Rufly \& W. Hartup (Eds.), Social cognition and social development: A socio-cultural perspective (pp. 236-274). New York: Cambridge.

Hoffman, M. L. (1994). Discipline and internalization. Developmental Psychology, 30(1), 26-28.

Jodelet, D. \& Moscovici, S. (1990). Les représentations sociales dans le champ social. Revue internacionale de psychologie sociale, 3(3), 285-288.

Joffe, H. (2003). "Eu, não", "o meu grupo não". Representações sociais transculturais da AIDS. Em Guareschi, P. \& Jovchelovitchi, S. (Orgs.), Textos em Representações Sociais ( $8^{\mathrm{a}}$ ed.), (pp. 297-322). Petrópolis: Vozes.

Lima, S. C. P. (2003). "O bem e o mal da lei": A liberdade assistida sob a perspectiva do adolescente infrator. Dissertação de Mestrado Não-Publicada, Programa de Pós-Graduação em Serviço Social, Universidade Federal de Pernambuco, Pernambuco.

Moreira, A. S. P.(Org). (2001) Representações Sociais: Teoria e Prática. João Pessoa: Universitária.

Pinheiro, D. P. N. (2003). Estilo parental: uma análise qualitativa. Dissertação de Mestrado não Publicada, Programa de PósGraduação em Psicologia da infância e da adolescência, Universidade Federal do Paraná, Paraná.

Rodrigues, M. M. P. \& Trindade, Z. A. (1999). Em nome do pai e do filho: relações afetivas e instrumentais. Em P. R. M. Menandro, Z. 
A. Trindade \& E. B. Borloti (Orgs.), Pesquisa em Psicologia: recriando métodos (pp. 125-139). Vitória: CAPES.

Santana, J. P., Doninnelli, T. M., Frosi, R. V. \& Koller, S. H. (2005). Os adolescentes em situação de rua e as instituições de atendimento: utilizações e reconhecimento de objetivos. Psicologia Reflexão e Crítica, 18(1), 134-142.

Sant'Ana, M. T. P. (2003). Representações sociais de conselheiros tutelares sobre o adolescente: relatos de uma prática. Dissertação de Mestrado, Programa de Pós-Graduação em Psicologia, Universidade Federal do Espírito Santo, Espírito Santo.

Santos, M. F. S., Novelino, A. M. \& Nascimento, A. P. S. (2001). O mito da maternidade: discurso tradicional sob roupagem modernizante. Em A. S. Moreira (Org.), Representações sociais: teoria e prática (pp. 269-293). João Pessoa:UFPB.

Santos, M. F. S. \& Aléssio, R. L. S. (2006). De quem é a culpa? Representações sociais de pais das zonas rurais e urbanas sobre adolescência e violência. Em A. M. O. Almeida, M. F. S. Santos, G. R. S. Diniz \& Z. A. Trindade (Orgs.), Violência, exclusão social e desenvolvimento humano. Estudos em representações sociais. (pp. 111-134). Brasília:UnB.
Trindade, Z. A. (1991). As representações sociais de paternidade e da maternidade: implicações no processo de aconselhamento genético. Tese de Doutorado não publicada, Instituto de Psicologia, Universidade de São Paulo, São Paulo.

Trindade, Z. A. (1998). Reflexão sobre o estatuto das práticas na teoria das representações sociais. Anais do Simpósio Internacional sobre representações sociais: questões epistemológicas, 1 (pp. 18-28). Natal, RN.

Vala, J. (1996). As representações sociais no quadro dos paradigmas e metáforas da Psicologia Social. Em L. Camino (Org.), Conhecimento do outro e a construção da realidade social: uma análise da percepção e da cognição social. Monografias em Psicologia Social (pp.119-159). João Pessoa: Universitária.

Weber, L. N. D., Viezzer, A. P. \& Bradenbrug, O. J. (2004). O uso de palmadas e surras como práticas educativas. Estudos de Psicologia, 9(2), 227-237.

Recebido em 26/10/2007 Aceito em 02/05/2008

\section{Endereço para correspondência :}

Zeidi Araujo Trindade. Programa de Pós-Graduação em Psicologia (PPGP), Centro de Ciências Humanas e Naturais (CCHN), Universidade Federal do Espírito Santo (UFES), Av. Fernando Ferrari, 514, Goiabeiras, CEP: 29075-910, Vitória-ES, Brasil. E-mail: zeidi.trindade@gmail.com 